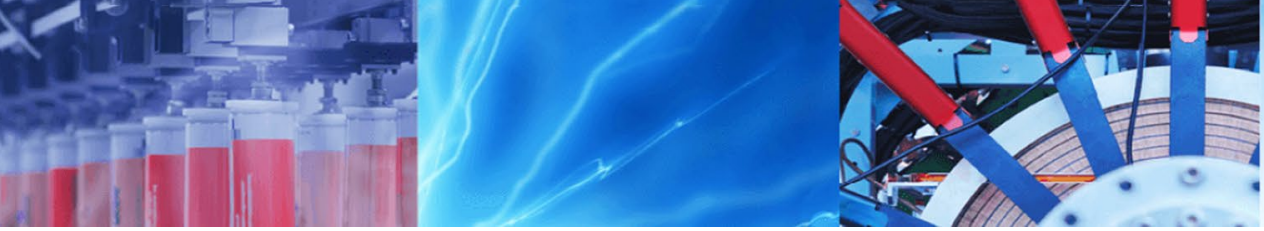

Case Study

\title{
The influence of the regenerative braking on the overall energy consumption of a converted electric vehicle
}

\author{
Naili Huda ${ }^{1}$ Sunarto Kaleg ${ }^{1}$ Abdul Hapid ${ }^{1}$ - M. Redho Kurnia ${ }^{1}$. Alexander Christantho Budiman ${ }^{1}$ (I)
}

Received: 28 November 2019 / Accepted: 2 March 2020 / Published online: 11 March 2020

(c) Springer Nature Switzerland AG 2020

\begin{abstract}
Electrical energy consumption of a converted electric vehicle in the real-world environment has been examined. The objective of such test is to compare the overall energy consumption of a vehicle with and without regenerative braking features. For each test, sets of data such as the total testing time, the batteries charge and/or discharge power, and the vehicle mileage were collected and analyzed to determine the energy consumption. The reliability of the data was tested using confidence intervals, which could be used as an indication of the level of confidence that the average value taken could represent the average population. The average value of energy consumption in the vehicles with and without regenerative braking is $145.26 \mathrm{Wh} / \mathrm{km}$ and $154.79 \mathrm{Wh} / \mathrm{km}$, respectively. The difference between the average energy consumption from those two conditions, which is $9.53 \mathrm{Wh} / \mathrm{km}$, has $95 \%$ probability to be accurate, as indicated by the confidence intervals test. This shows a decrease in electrical energy consumption by about $6.16 \%$, which indicates an enhancement in mileage or vehicles efficiency.
\end{abstract}

Keywords Electric vehicle $\cdot$ Regenerative braking $\cdot$ Real-world environment $\cdot$ Confidence intervals

\section{Introduction}

Electric vehicles (EVs) are vehicles that utilize electrical energy to supply the driving components. The source of electrical energy can be connected directly to the grid or stored in the battery. Traction effort of an electric vehicle is supplied from one or several electric motors [1]. In terms of electric vehicles with batteries, the overall mileage in every charging depends on the battery capacity, the driver's driving style, and the efficiency of the driving components. Increasing the battery capacity would increase the mileage, but it comes with higher cost and longer charging time. Meanwhile, to condition the driver's driving style may also affect the amount of discharge from the battery, but this method is technically difficult to apply due to its subjectivity factor. Hence, the most realistic way to optimize the EV mileage is by increasing the efficiency of its driving components.

Previous studies show various ways to improve the efficiency of the driving components. A simulation study on two motors coupled with planetary gear and parallel transmissions shows a higher efficiency compared to EV powered by a single motor [2]. Traffic signals can be used to increase the efficiency of EV by regulating the speed based on the actual traffic status [3]. Appropriate information about environmental conditions or the batteries states of charge (SOC) could assist drivers to adjust their driving style at the best possible way to cover more miles [4]. The working temperature of the battery also affects the mileage. The use of coolant is found to be more effective in maintaining an acceptable temperature range rather than a passive cooling system from a solid material. The flow pattern of the coolant affects the thermal profile of the

Alexander Christantho Budiman, alex002@lipi.go.id| ${ }^{1}$ Research Center for Electrical Power and Mechatronics, Indonesian Institute of Sciences, Jl. Sangkuriang, Bandung, Jawa Barat 40135, Indonesia. 
battery cells [5]. A strategy to regulate the air-conditioning system of the EV might also influence the mileage, since hot or cold weather conditions would affect the electrical load of the air-conditioning system [6]. These studies show that the more efficient use of electrical energy inside the battery would directly increase the mileage of electric vehicles.

One alternative to improve the efficiency of the EV driving components is by means of regenerative braking. The basic principle of this technology is to convert the kinetic energy from inertia during deceleration/braking into electrical energy that can be utilized again by the driving components [7]. An example of the use of regenerative braking is in converted hybrid heavy vehicles with notably lower fuel consumption than the other, similar type of vehicles [8]. The advantage of regenerative braking is the ability to improve the efficiency of EV without any addition of components, especially for the induction and permanent magnet electric motors. The three-phase induction motor operates on a four-quadrant basis. The first and third quadrants are the motor operation modes, and the second and fourth quadrants are the operating modes of regenerative braking [9]. To activate or deactivate the regenerative braking system, users could simply adjust the setting of these modes manually as they connect the motor controller to the computer software.

Further study about regenerative braking is to obtain the best possible energy conversion efficiency. The amount of energy generated from regenerative braking can be controlled by estimating the vehicle longitudinal velocity and from the information of vehicle states [10]. Fuzzy adaptive control algorithms can be used to increase the generation of energy from regenerative braking while reducing the weight of the vehicle [11]. The amount of energy generated by regenerative braking can be linked to the variations of the brake pedal depression [12]. The regenerative braking efficiency can be improved further by applying the predictive control theory by means of determining hydraulic braking torque and motor braking torque [13].

In connection with an experimental study, the methods to generate regenerative braking energy efficiently are developed on the actual object, that is, the vehicle. The vehicle is tested on a chassis dynamometer with a certain driving cycle procedure so that the energy efficiency values can be obtained and calculated from some comparable methods [14]. Scientifically, those experimental results can be used as research achievement. However, often these experimental results might not reflect the actual energy efficiency when tested in the real environment. The electrical energy consumption of EV tested in the real-world environment might be beneficial as a reference used by stakeholders to establish transportation policies, especially on energy, environmental, and economic aspects [15]. However, the published data obtained from tests on the real-world environment are still relatively rare, lack of accuracy, and hard to replicate. An analysis of the characteristics of energy consumption is the main basis in planning infrastructure locations, adjusting the driving style, and finding the routes with the lowest energy consumption [16]. Analysis using multivariate linear regression (MLR) model is one of the methods to estimate the electrical energy consumption of vehicle mileage [17]. Regression analysis can be used to obtain the energy consumption characteristics of EV by overriding any driving conditions [18]. Another test in the real-world environment has been conducted according to the Chinese Typical City Regenerative Driving Cycle (CTCRDC) standard by evaluating the increase in energy transfer efficiency and mileage due to the regenerative braking [19]. The effect of vehicle accessories systems to the efficiency of regenerative braking has also been studied in the real-world environment using China City Bus Typical Driving Cycle [20].

In this study, the vehicle testing was carried out in the real-world environment, that is, on the urban roads. Such roads were chosen because it is already became the focus of research in many countries, in an attempt to reduce vehicle emissions. The electric vehicles test on urban roads was also focused in various objectives and targets. The rapid growth of EV in China could potentially be challenging with regard to the construction of charging infrastructure and in terms of electricity grid stability [21]. Meanwhile, the energy consumption of the electric freight vehicles (EFVs) in Rome is estimated and validated based on real-world data [22]. The energy consumption of battery electric vehicle from Shanghai, China, was obtained from an analysis of four factors, i.e., trip distance, speed, initial SOC, and ambient temperature [17]. The energy consumption of electric trucks in Gothenburg, Sweden, has been estimated based on a comparison between numerical simulations and the actual consumption data measured on the public transport route [23].

Despite all those recent studies, the energy measurements that can be obtained from the regenerative braking system, especially in the converted gasoline-fueled into electric vehicle, are still rare in the literature. The previous research on regenerative braking and any other improvement methods are mainly dedicated to common EV products or prototypes, not on the converted EV from gasolinebased vehicle. On the other hand, such EV conversion is actually one way to implement the electric driving technology at notably lower cost. Such conversion and revitalization can also be done on the old electric buses and minibuses by means of replacing lead-acid batteries with lithium-ion batteries to enable fast charging features [24]. Furthermore, there is also a growing demand to convert 
the gasoline-fueled to the electric public transport due to its positive benefits to the environment [25]. Therefore, the energy measurement and vehicle performance on the converted $\mathrm{EV}$ with regenerative braking system in the realworld environment needs to be done, which is the main objective of this study.

\section{Methods}

\subsection{Calculation of the vehicle energy consumption}

A Toyota Kijang Super car gasoline-fueled passenger vehicle has been converted into an electric vehicle. The original 1,500 cc gasoline-fueled engine, manufactured in 1994, has been replaced with a three-phase induction electric motor. Fuel tanks and exhaust parts are some of the other components that have been removed from the car. These components are replaced with electric motors, batteries, motor controllers, and other electric vehicle components. The vehicle has a new specification with an electric drive system as tabulated in Table 1, and the photograph of the converted car is presented in Fig. 1.

The converted car in this study uses Curtis 1238-7501 AC induction motor controller manufactured by Curtis Instruments, Inc. This motor controller has a vector control technology which can manipulate the magnitude, frequency, and the phase of the motor controller variables to produce a high-efficiency electrical motor. These motor controller variables above can be adjusted as needed. A Curtis 1314 Programming station software application is used to connect the motor controller with a laptop via serial communication. The software allows monitoring and storing data (as data loggers) of each variables when the car is in use. Before testing, the laptop and motor controller were connected, and the data logger feature in the software was prepared. The variables stored by the data logger are the battery voltage as well as the electric current from

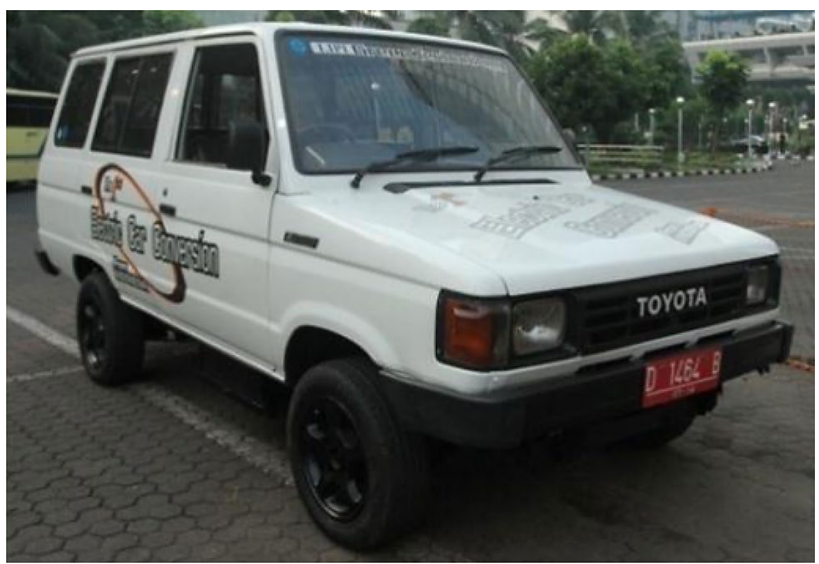

Fig. 11994 Toyota Kijang Super gasoline-to-electric converted car [26]

and to the battery. Power was calculated by multiplying the voltage and current from the battery. The regenerative braking power means the electric power that charges the battery when the motor controller is in regenerative mode.

Sixteen units of lead-acid batteries were stored in several compartments outside the cabin. Four battery units were placed in the electric motor compartment area, two battery units in each side under the floor, and eight battery units under the floor replacing the fuel tank. The drivetrain arrangement of the 1994 Toyota Kijang Super gasoline-toelectric converted car is longitudinal with rear wheel drive (RWD). Therefore, the position of the electric motor follows the longitudinal position of the transmission. The original manual transmission of the 1994 Toyota Kijang Super was not changed. There was also no change with regard to the gear ratio in the transmission of this car; even the flywheel and clutch were still used. The transmission ratio of the 1994 Toyota Kijang Super gasoline-to-electric converted car is shown in Table 2. The schematic drawing of the main components is depicted in Fig. 2.
Table 1 Specifications of the retrofitted 1994 Toyota Kijang Super electric vehicle [26]

\begin{tabular}{ll}
\hline Name of components & Specifications \\
\hline Electric motor type & Three-phase AC induction \\
Electric motor maximum power & $52 \mathrm{HP}$ \\
Electric motor maximum torque & $156 \mathrm{Nm}$ \\
Electric motor maximum rotation & $6.500 \mathrm{rpm}$ \\
Battery type & Deep cycle lead acid \\
Battery nominal voltage & $96 \mathrm{Vdc}$ \\
Battery nominal capacity & $235 \mathrm{Ah}$ (135 min. @ 75A) \\
Charger Power & $2.800 \mathrm{~W}$ (single phase) \\
Other features & $400 \mathrm{~W}$ DC/DC converter, electrohydraulic \\
& power steering and electric vacuum \\
& brake
\end{tabular}


Table 2 Transmission ratio of the converted car used in this study

\begin{tabular}{ll}
\hline Gears & Ratio \\
\hline 1st & 4.015 \\
2nd & 2.509 \\
3rd & 1.533 \\
4th & 1.000 \\
Reverse & 4.571 \\
Final gear & 4.778 \\
\hline
\end{tabular}

The 1994 Toyota Kijang Super has an empty weight (vehicle curb weight) of around $1200 \mathrm{~kg}$. The engine, fuel lines, radiator, and exhaust lines were removed during the retrofit process and subsequently replaced by 16 units of lead-acid batteries, electric motors, motor controllers, and chargers resulting in an empty vehicle weight of the gasoline-to-electric converted car approximately $1600 \mathrm{~kg}$. The lead-acid battery used is the Deep Cycle 6D135 from INCOE.

The converted car was tested by comparing the value of electrical energy consumption with and without the regenerative braking feature. This regenerative braking function was set to operate automatically when the acceleration pedal is not being pushed. Hence, the inertia of the vehicle can be converted into electrical energy that is transferred back into the battery. Certainly, the energy conversion results in deceleration of the car. The amount of regenerative braking electric current was set to a maximum of $10 \%$ of the traction current which is around $55 \mathrm{~A}$. The value of the regenerative braking current is smaller than the current required for the traction, so the braking effect on the car is similar to an engine brake on a conventional car. When using a lead-acid battery for traction, increasing the regenerative braking current too much is not recommended, considering a potential over-current on charging the lead-acid battery, which can cause the electrolyte liquid to boil and cause degradation of the battery's life.

A 12.4-km route in Bandung city was designated as a vehicle test route, as shown in Fig. 3. It started from the laboratory and then went toward the main roads before finally returned back to its original place. It is necessary to determine the route and operation during the testing beforehand, since these are significant factors that contribute to the data obtained, as the previous study in Southern California suggests [27]. Some variables that were fixed during the tests are listed in Table 3. Prior to testing, the battery was fully charged to prevent the vehicle from breaking down during the test period.

The data taken from the testing are: test date and time, numbers of datum, duration of each test, total battery charge/discharge power, and vehicle mileage. The mileage data were collected from the odometer reading before and after the test. The remaining data were obtained from the data logger in a laptop using a motor controller program. The test was carried out only once in a day. All the data were processed to calculate the value of electric vehicle energy consumption at each test using Eqs. (1)-(4), where $t$ is the duration of test (in hour), $n$ is the number of datum population, and $D$ is the sampling time, which was set as a constant of $300 \mathrm{~ms}$ throughout the study.

$t=\sum_{i=1}^{n} D_{i} / 3.6 \times 10^{6}$

The average battery charge/discharge power value $P_{\mathrm{r}}$ is defined to indicate the power value which represents each test:
Fig. 2 Main components drawing of the gasoline-toelectric converted car used in this study

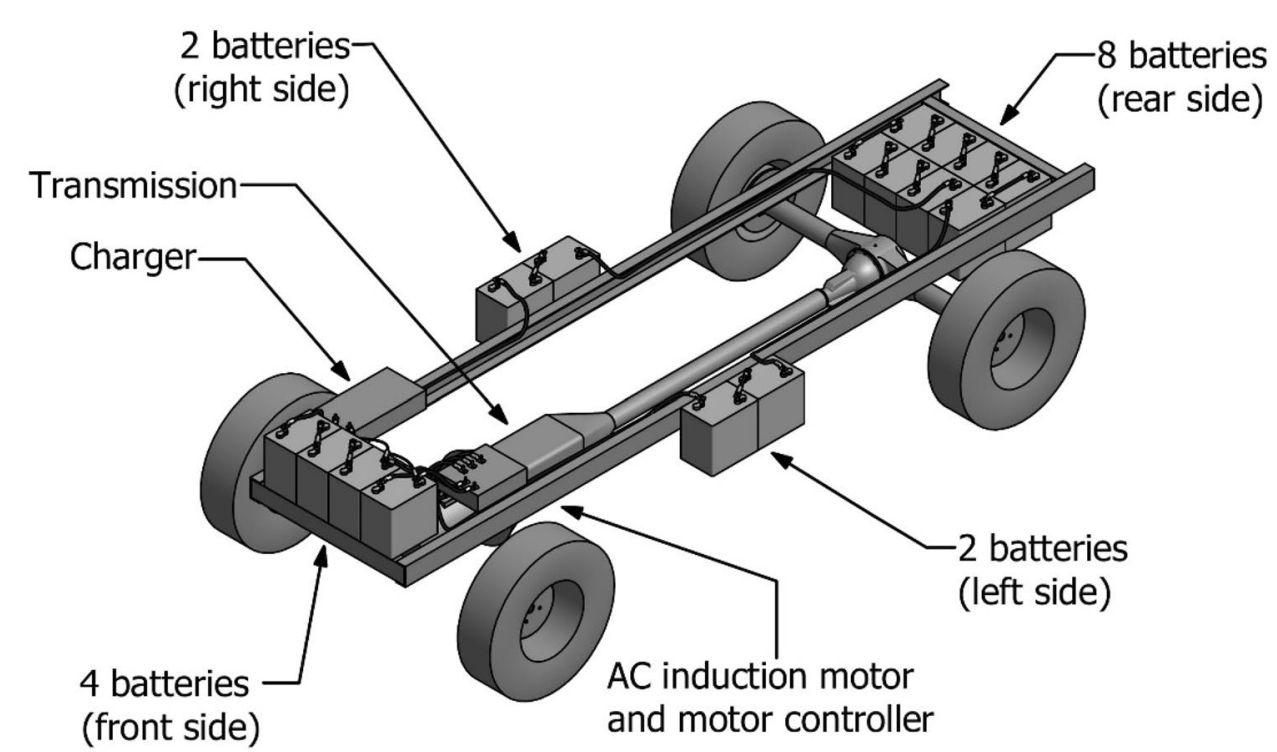


Fig. 3 The map of Bandung showing the test route. The location sign on the upper right indicates the authors' laboratory, where the trip started and finished

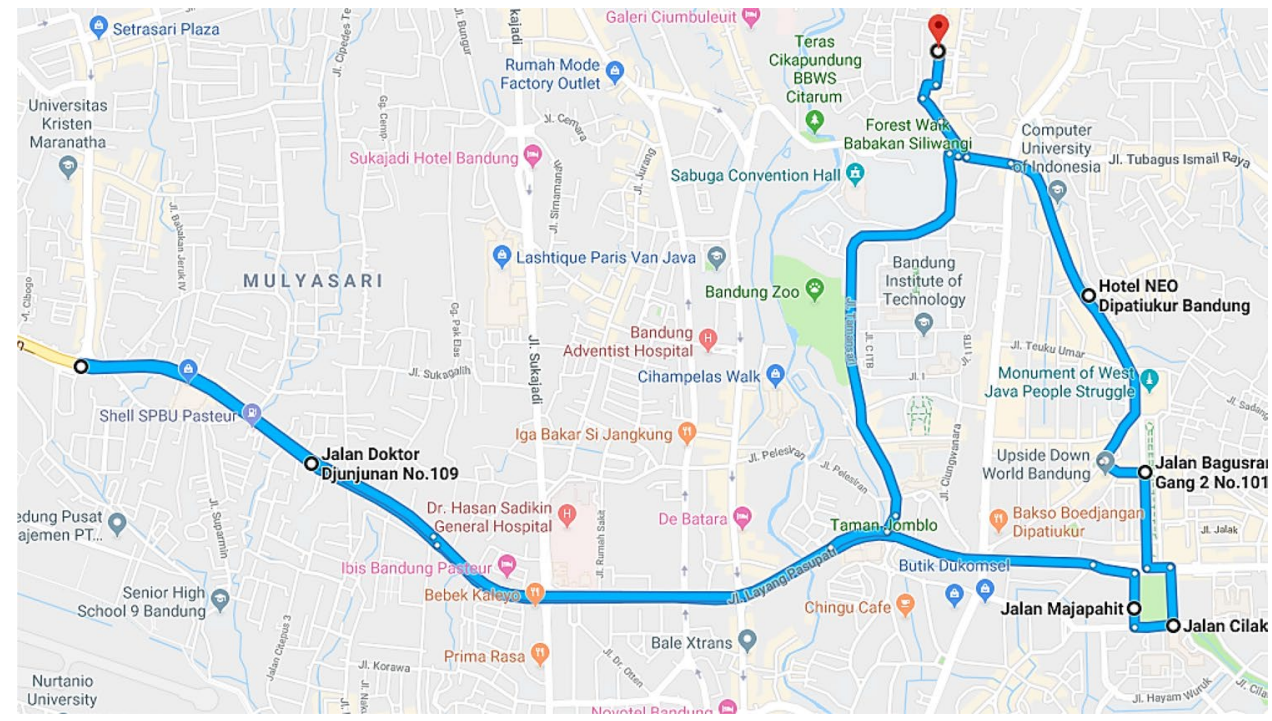

Table 3 Values of some variables used in all tests

\begin{tabular}{ll}
\hline Variables & Values \\
\hline Maximum vehicle speed & $60 \mathrm{kph}$ \\
Vehicle load & $55 \mathrm{~kg}$ and $43 \mathrm{~kg}$ (one \\
& driver and one pas- \\
& senger) \\
Test starting time & $09: 00 \mathrm{AM}$ \\
Total data sets & 32 \\
\hline
\end{tabular}

$P_{\mathrm{r}}=\frac{\sum_{i=1}^{n} P_{i}}{n}$

where $P_{i}$ is the instantaneous power on each datum (W). Any acceleration and deceleration would cause fluctuations in this instantaneous power $P_{i}$.

The amount of electrical energy required during each test $E_{\mathrm{t}}$ in a day is defined as the multiplication of the average power $P_{\mathrm{r}}$ with the total hours of testing $t$.

$E_{\mathrm{t}}=P_{\mathrm{r}} \times t$

$E_{\mathrm{t}}$ is the total electrical energy needed throughout the test $(\mathrm{Wh})$, while the vehicle electrical energy consumption per $\mathrm{km} E_{\mathrm{c}}$ is obtained from the total electrical energy $E_{\mathrm{t}}$ divided by the distance covered by the vehicle (trip).

$E_{\mathrm{c}}=E_{\mathrm{t}} /$ trip

$E_{c}$ is therefore defined as the electric energy consumption per $\mathrm{km}$ for each test $(\mathrm{Wh} / \mathrm{km})$, and trip is the difference of the odometer reading before and after each test $(\mathrm{km})$.

The value of electricity consumption is recapitulated in a table, and then, its standard deviation value is determined. The standard deviation is used for assessment that the value of the average electricity consumption can represent the value of vehicle energy consumption with or without the regenerative braking feature. The average value of electrical energy consumption with $\left(E_{\text {regen }}\right)$ or without $\left(E_{\text {noregen }}\right)$ regenerative braking features is shown in Eqs. (5) and (6).

$E_{\text {regen }}=\frac{\sum_{i=1}^{32} E_{c 1_{i}}}{32}$

$E_{\text {noregen }}=\frac{\sum_{i=1}^{32} E_{c 2_{i}}}{32}$

$E_{\mathrm{c} 1}$ and $E_{\mathrm{c} 2}$ are the values of $E_{\mathrm{c}}$ for each set of tests (one set consists of daily measurements in a total period of 32 days).

\subsection{Confidence intervals for the population mean value}

The reliability of data needs to be tested after calculating the mean and standard deviation of a sample. Reporting the population average in a measurement is more convincing if data reliability test is added, e.g., confidence intervals. Confidence intervals are a range of values that can be believed (up to a certain percentage) to contain the average value of population. Confidence intervals are often used for a normally distributed data. The normal distribution equation $(f(x))$, which is a continuous probability distribution in the form of a bell curve, is shown in Eq. (7).

$f(x)=\frac{1}{s \sqrt{2 \pi}} e^{-\frac{(x-\bar{x})^{2}}{2 s^{2}}}$ 

population average, respectively, while $s$ is the standard deviation of the population [28]. If the data population forms a normal distribution, then the upper and lower limit of the confidence intervals is determined by Eq. (8).

$P \%=\bar{x} \pm \frac{z_{P \%} s}{\sqrt{k}}$

$P \%$ is the value of the confidence interval set at $95 \%$, $\bar{x}$ is the average measurement data, $s$ is the population standard deviation, $z_{\mathrm{P} \%}$ is the $z$ value at the percentage of confidence interval chosen (at $95 \%, z$ value is 1.96), and $k=32$. It should be noted that $s / \sqrt{k}$ is the standard error of the data population [29]. Confidence intervals can also be used to determine the difference between the two population averages with the same treatment. The difference is expressed in the following confidence intervals formula (Eq. (9)). $\bar{x}_{1}$ and $\bar{x}_{2}$ denote the average measurement data for the first and second object, respectively. Meanwhile, $s_{1}$ and $s_{2}$ denote the standard deviation for the first data and the second data, respectively.

$P \%=\left(\bar{x}_{1}-\bar{x}_{2}\right) \pm z_{\mathrm{p} \%} \sqrt{\frac{s_{1}^{2}}{k_{1}}+\frac{s_{2}^{2}}{k_{2}}}$

In this study, $\bar{x}_{1}$ and $\bar{x}_{2}$ denote the average of energy consumption with and without the regenerative braking feature, while $s_{1}$ and $s_{2}$ denote the standard deviation of $\bar{x}_{1}$ and $\bar{x}_{2}$, respectively. $k_{1}$ and $k_{2}$ denote the total numbers of datum used, which is 32 (total days, as shown in Table 4).

\section{Results and discussion}

The measured energy consumption for regenerative and without regenerative braking is tabulated in Table 4, and its normal distribution is plotted in Fig. 4. It can be seen that both sets of data form a relatively symmetrical, normal distribution. The average population value is depicted by the vertical line in the middle.

Table 5 shows the range of energy consumption of 143.94-146.58 Wh/km for testing with regenerative braking, and it is with a probability of $95 \%$ true that the actual average energy consumption is within this range. Similarly, the results from vehicle testing without regenerative braking show the range of 153.30-156.27 $\mathrm{Wh} / \mathrm{km}$. Therefore, it can be concluded that the average of energy consumption value for each test could be accepted to represent the population. Confidence intervals for differences between means indicate a range of 7.54-11.50 Wh/km, which also means that there is a $95 \%$ probability that the actual difference in the average

$x$ and $\bar{x}$ are measurement data for each sample and

Table 4 Results from the measurement of energy consumption for with $\left(E_{\text {regen }}\right)$ and without regenerative braking $\left(E_{\text {noregen }}\right)$ (a) (n) 
Fig. 4 Measurement results show a normal distribution of the energy consumption of a converted electric vehicle car under investigation. Solid line indicates the energy consumption with regenerative braking feature $E_{\text {regen, }}$ while broken line indicates the energy consumption without the regenerative braking $E_{\text {noregen. }}$ The average energy consumption value, that is, 145.26 and 154.79 $\mathrm{Wh} / \mathrm{km}$ for $E_{\text {regen }}$ and $E_{\text {noregen, }}$ respectively, is shown by the gray solid vertical line
Table 5 The average of electricity consumption and standard deviation

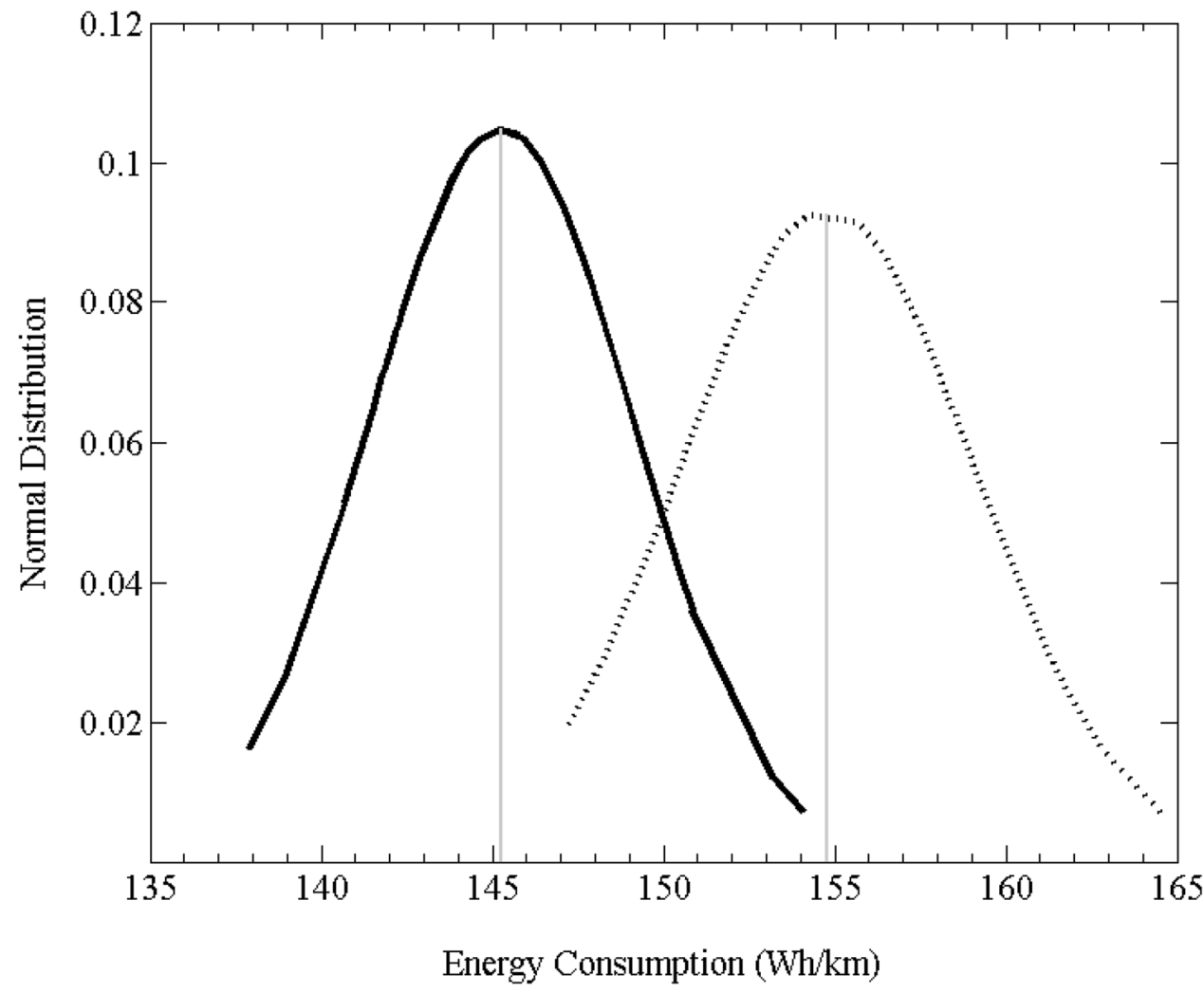

\begin{tabular}{lll}
\hline & $E_{\text {regen }}$ & $E_{\text {noregen }}$ \\
\hline Average of energy consumption $(\mathrm{Wh} / \mathrm{km})$ & 145.26 & 154.79 \\
Standard deviation & 3.81 & 4.27 \\
Confidence intervals (95\%) & $143.94-146.58$ & $153.30-156.27$ \\
Confidence intervals for differences between means & $7.54-11.50$ & \\
$(95 \%)$ & & \\
\hline
\end{tabular}

\section{Conclusions}

Observation on electrical energy consumption in a converted gasoline-fueled vehicle into electric vehicle has been carried out by testing in the real-world environment. The 12.4-km road in Bandung, Indonesia, is designated as a vehicle test route. Some variables are set, and the same value is approximated throughout the testing. Test date and time, numbers of datum, duration of each test, total battery charge/discharge power, and vehicle mileage were recorded and used to calculate the electricity consumption data for each run. The reliability of the data is confirmed by means of confidence intervals. The calculation of confidence intervals is used as an indication of the level of confidence that the average value taken could represent the average population. Testing of the vehicle with the regenerative braking feature shows a
$95 \%$ probability that its average energy consumption is in the range $143.94-146.58 \mathrm{Wh} / \mathrm{km}$. On the other hand, the vehicle without regenerative braking would be in the range of $153.30-156.27 \mathrm{Wh} / \mathrm{km}$. Confidence intervals also show that, for differences between means, there is $95 \%$ probability that the difference in the average energy consumption of the two tests will be found in the range $7.54-11.50 \mathrm{Wh} / \mathrm{km}$. The difference between averages of energy consumption due to the presence of regenerative braking is $9.53 \mathrm{Wh} / \mathrm{km}$, so it could be accepted to reflect the difference in the average energy consumption from the two tests. Based on the data analysis above, the use of regenerative braking technology on the retrofitted car under investigation produces lower electricity consumption by $9.53 \mathrm{Wh} / \mathrm{km}$ or $6.16 \%$. The decrease in electricity consumption equals to the increase the efficiency of vehicles. Increasing vehicle efficiency can produce more mileage with the same energy capacity. 
Acknowledgements The authors would thank the Indonesian Institute of Sciences, especially the Research Centre for Electrical Power and Mechatronics for the financial support.

\section{Compliance with ethical standards}

Conflict of interest The authors declare that they have no conflict of interest.

\section{References}

1. Husain I (2003) Electric and hybrid vehicles design fundamentals. CRC Press, Boca Raton

2. Wu J, Liang J, Ruan J et al (2018) Efficiency comparison of electric vehicles powertrains with dual motor and single motor input. Mech Mach Theory 128:569-585. https://doi.org/10.1016/j. mechmachtheory.2018.07.003

3. Madhusudhanan AK (2019) A method to improve an electric vehicle's range: efficient cruise control. Eur J Control 48:83-96. https://doi.org/10.1016/j.ejcon.2018.12.006

4. Mruzek M, Gajdáč I, Kučera L', GajdošíkT (2017) The possibilities of increasing the electric vehicle range. Procedia Eng 192:621625. https://doi.org/10.1016/j.proeng.2017.06.107

5. Smith J, Hinterberger M, Schneider C, Koehler J (2016) Energy savings and increased electric vehicle range through improved battery thermal management. Appl Therm Eng 101:647-656. https://doi.org/10.1016/J.APPLTHERMALENG.2015.12.034

6. Zhang Z, Wang D, Zhang C, Chen J (2018) Electric vehicle range extension strategies based on improved $A C$ system in cold climate-a review. Int J Refrig 88:141-150. https://doi. org/10.1016/j.jirefrig.2017.12.018

7. Zhang L, Cai X (2018) Control strategy of regenerative braking system in electric vehicles. Energy Procedia 152:496-501. https ://doi.org/10.1016/j.egypro.2018.09.200

8. Chu C, Chou C, Chen J et al (2011) Study of an electric vehicle drive dynamic testing system with energy recovery. Procedia Eng 23:608-615. https://doi.org/10.1016/j.proeng.2011.11.2554

9. Erlston LJ, Miles MD (2018) Retrofittable regenerative braking in heavy vehicle applications. 724

10. Chen J, Yu J, Zhang K, Ma Y (2018) Control of regenerative braking systems for four-wheel-independently-actuated electric vehicles. Mechatronics 50:394-401. https://doi.org/10.1016/j. mechatronics.2017.06.005

11. Wen HH, Chen W, Hui J (2018) A single-pedal regenerative braking control strategy of accelerator pedal for electric vehicles based on adaptive fuzzy and control algorithm. Energy Procedia 152:624-629. https://doi.org/10.1016/j.egypro.2018.09.221

12. Godfrey AJ, Sankaranarayanan V (2018) A new electric braking system with energy regeneration for a BLDC motor driven electric vehicle. Eng Sci Technol Int J 21(4):704-713. https://doi. org/10.1016/j.jestch.2018.05.003

13. Xu W, Chen H, Zhao H, Ren B (2019) Torque optimization control for electric vehicles with four in-wheel motors equipped with regenerative braking system. Mechatronics 57:95-108. https:// doi.org/10.1016/j.mechatronics.2018.11.006

14. Lv C, Zhang J, Li Y, Yuan Y (2014) Mechanism analysis and evaluation methodology of regenerative braking contribution to energy efficiency improvement of electrified vehicles. Energy Convers Manag 92:469-482. https://doi.org/10.1016/j.encon man.2014.12.092
15. Wu D, Aliprantis DC, Gkritza K (2011) Electric energy and power consumption by light-duty plug-in electric vehicles. IEEE Trans Power Syst 26(2):738-746. https://doi.org/10.1109/TPWRS .2010 .2052375

16. Zhang $R$, Yao E (2015) Electric vehicles' energy consumption estimation with real driving condition data. Transp Res Part D Transp Environ 41:177-187. https://doi.org/10.1016/j.trd.2015.10.010

17. Qi Z, Yang J, Jia R, Wang F (2018) Investigating real-world energy consumption of electric vehicles: a case study of Shanghai. Procedia Comput Sci 131:367-376. https://doi.org/10.1016/j.procs .2018.04.176

18. Yuan X, Zhang C, Hong G et al (2017) Method for evaluating the real-world driving energy consumptions of electric vehicles. Energy 141:1955-1968. https://doi.org/10.1016/j.energ y.2017.11.134

19. Qiu C, Wang G (2016) New evaluation methodology of regenerative braking contribution to energy efficiency improvement of electric vehicles. Energy Convers Manag 119:389-398. https:// doi.org/10.1016/j.enconman.2016.04.044

20. Li N, Zhang J, Zhang S et al (2018) The influence of accessory energy consumption on evaluation method of braking energy recovery contribution rate. Energy Convers Manag 166:545-555. https://doi.org/10.1016/j.enconman.2018.04.040

21. Zhang X, Zou Y, Fan J, Guo H (2019) Usage pattern analysis of Beijing private electric vehicles based on real-world data. Energy 167:1074-1085. https://doi.org/10.1016/j.energy.2018.11.005

22. Fiori C, Marzano V (2018) Modelling energy consumption of electric freight vehicles in urban pickup / delivery operations: analysis and estimation on a real-world dataset. Transp Res Part D 65(October):658-673. https://doi.org/10.1016/j. $\operatorname{trd}$ 2018.09.020

23. Basso R, Kulcsár B, Egardt B et al (2019) Energy consumption estimation integrated into the electric vehicle routing problem. Transp Res Part D 69:141-167. https://doi.org/10.1016/j. $\operatorname{trd}$.2019.01.006

24. Alessandrini A, Cignini F, Ortenzi F et al (2017) Advantages of retrofitting old electric buses and minibuses. Energy Procedia 126:995-1002. https://doi.org/10.1016/j.egypro.2017.08.260

25. Huda N, Hassall KP, Kaleg S, Hapid A (2015) Economic Valuation of Hypothetical Paratransit Retrofitting. J Mechatron Electr Power Veh Technol 6(1):49-56. https://doi.org/10.14203 /j.mev.2015.v6.49-56

26. Kaleg S, Hapid A, Kurnia MR (2015) Electric vehicle conversion based on distance, speed and cost requirements. Energy Procedia. https://doi.org/10.1016/j.egypro.2015.03.276

27. Qi X, Wu G, Boriboonsomsin K, Barth MJ (2018) Data-driven decomposition analysis and estimation of link-level electric vehicle energy consumption under real-world traffic conditions. Transp Res Part D 64:36-52. https://doi.org/10.1016/j. trd.2017.08.008

28. Zhang C, Hu X, Wu Z, Li Q (2018) Influence of grain size on granite strength and toughness with reliability specified by normal distribution. Theor Appl Fract Mech 96:534-544. https://doi. org/10.1016/j.tafmec.2018.07.001

29. Jones $D(2002)$ Statistical estimation using confidence intervals. In: Pharmaceutical statistics, 1st edn. Pharmaceutical Press, pp 135-154

Publisher's Note Springer Nature remains neutral with regard to jurisdictional claims in published maps and institutional affiliations. 